\title{
MAR PRÓXIMO, CIDADE DISTANTE: ECONOMIA CRIATIVA E REGENERAÇÃO URBANA EM LISBOAE RIO DE JANEIRO
}

Diego Santos Vieira de Jesus*

\begin{abstract}
Resumo
Com base no referencial teórico de Charles Landry e da colaboração do autor com Franco Bianchini, o objetivo do trabalho é explicar os méritos e as limitações de processos de regeneração de territórios urbanos que tiveram como um dos eixos condutores o estímulo ao desenvolvimento da economia criativa: a Zona de Intervenção da Expo, em Lisboa, e a Zona Portuária do Rio de Janeiro. A metodologia utilizada baseou-se em uma pesquisa bibliográfica, com a mobilização de informações qualitativas. Aponta-se que os resultados ficaram aquém do esperado por conta das dificuldades de integração dessas regióes com seus entornos, dos problemas de fixação de profissionais criativos e do baixo estímulo ao engajamento da população local nas principais atividades relacionadas aos setores criativos.
\end{abstract}

Palavras-chave: Economia Criativa. Regeneração Urbana. Lisboa. Rio de Janeiro.

\footnotetext{
* Doutor em Relações Internacionais pela Pontifícia Universidade Católica do Rio de Janeiro (PUC-Rio) e docente e pesquisador do Programa de Mestrado Profissional em Gestão da Economia Criativa da Escola Superior de Propaganda e Marketing do Rio de Janeiro (ESPM-Rio).E-mail: dvieira@espm.br
} 


\section{Introdução}

Em inúmeras cidades ao redor do mundo, o estímulo ao desenvolvimento da economia criativa serviu como um dos motores para processos de regeneração de territórios degradados. A economia criativa pode ser definida como um conjunto de atividades voltadas para a produção, a distribuição e o consumo de bens e serviços com base em textos, símbolos e imagens e nas atividades sustentadas na criatividade, aqui entendida como a expressão do potencial de realização de atividades geradoras de produtos tangíveis e à manipulação de símbolos e significados para a geração de inovações. Tal economia abarca setores como o artesanato, a moda, as indústrias culturais clássicas - do audiovisual, da música e do livro - e as indústrias dos softwares e dos jogos eletrônicos (MIGUEZ, 2007), bem como patrimônio material e imaterial, o design, a arquitetura e as artes do espetáculo. Nessa economia, as concepções estéticas e artísticas orientam o direcionamento de recursos, e o consumidor coloca-se como um agente na geração de valor econômico a partir da construção de sua identidade nos novos regimes de distinção simbólica (BENDASSOLLI et al.,2009). A economia criativa pode atribuir importância ao capital humano, ampliar o acesso ao consumo, desenvolver nichos culturais geradores de valor e trazer oportunidades para a formalização de pequenos negócios, a geração de renda e emprego e a expressão e a participação dos cidadãos na vida política (REIS, 2008). A promoção do desenvolvimento sob um prisma cultural, político e socioeconômico está fincada na sustentabilidade - para que se busque o desenvolvimento que atenda às necessidades do presente, sem comprometer a habilidade das futuras gerações de atender às suas próprias necessidades e na ligação transversal entre setores culturais, econômicos e políticos até então vistos como díspares (REIS, 2006).

Em uma perspectiva histórica, é possível afirmar que nos Estados lusófonos o incentivo à economia criativa foi gradualmente reconhecido como uma estratégia para o 
desenvolvimento, inclusive para a melhoria de condições de vida em áreas degradadas de centros urbanos. Mais recentemente, em 2015, o Encontro da Economia Criativa Lusófona (ECL) permitiu o contato de profissionais internacionais das artes, da cultura e da gestão de bens públicos dos Estados lusófonos para a troca de experiências e conhecimentos e a expansão de contatos e atividades relacionadas às indústrias criativas (ECL, 2015). O Encontro Luso-Brasileiro de Territórios Criativos em 2013 promoveu o intercâmbio de experiências e conhecimentos entre Portugal e Brasil sobre a criatividade como promotora de desenvolvimento urbano, segundo informa o site Comunidade dos países de língua portuguesa (CPLP, 2013). Porém, tanto para Portugal como para o Brasil, o incentivo à economia criativa já vinha servindo como uma das bases para processos de regeneração urbana e de promoção de desenvolvimento local e ainda vem promovendo grandes transformações em territórios e cidades nesses Estados, como se pode verificar em duas regiões originalmente degradadas e localizadas próximas ao mar: a Zona de Intervenção da Expo, em Lisboa, e a Zona Portuária da cidade do Rio de Janeiro.

A Exposição Internacional de Lisboa (Expo 98) também conhecida como Exposição Mundial de 1998, que ocorreu entre maio e setembro daquele ano - reuniu Estados do mundo inteiro com o objetivo de buscar soluções e iniciativas que pudessem despertar a consciência ambiental - um dos pilares da economia criativa - nos visitantes do evento. Para a realização da exposição, desenvolveu-se um projeto de regeneração urbana de uma área de cerca de 340 hectares, localizada na região oriental de Lisboa, junto ao rio Tejo. A celebração da posição geográfica e do legado histórico portugueses ocorreu com a expressão de sua capacidade urbanística e arquitetônica, que permitia gerar estrutura organizativa e econômico-financeira que abarcava os valores implicados na realização da exposição e trazia pré-condições para que atividades relacionadas à economia criativa pudessem ser desenvolvidas no local, tanto durante,como após a exposição, como a multiplicação das linhas de trem, o prolongamento do 
metrô, a criação de uma nova entrada para a área metropolitana de Lisboa pela Ponte Vasco da Gama, a remodelação das redes de tratamento de água, a implantação da rede de gás natural e de uma central incineradora de resíduos sólidos. O projeto urbano da Expo 98 aproveitou a infraestrutura legada da exposição - tanto o espaço edificado para a realização do evento como áreas residenciais, equipamentos, serviços, infraestrutura urbana, estacionamentos e zonas verdes - para tentar buscar a revalorização da relação da cidade com o rio, recuperar o ambiente e assegurar a integração daquele espaço no tecido da cidade, bem como a participação na sua identidade a fim de se definir uma centralidade alternativa na zona metropolitana de Lisboa. A requalificação urbanística e ambiental contribuiu também para a modernização e a internacionalização de Lisboa e para a atração de novos empreendimentos criativos para a região. As atividades culturais desenvolvidas nos equipamentos situados na área atraem cidadãos portugueses e turistas do mundo inteiro e movimentam milhões de euros por ano (SCHERER, 2003).

No fim da década de 2000, o Projeto Porto Maravilha formalmente denominado Operação Urbana Consorciada da Área de Especial Interesse Urbanístico da Região Portuária do Rio de Janeiro - recebeu destaque entre atores políticos, empresariado e sociedade civil após os resultados subótimos de uma série de projetos de proteção e regeneração desde meados da década de 1980. O objetivo principal do projeto - que incluiu os bairros da Saúde, Gamboa, Santo Cristo e parte dos bairros do Caju, São Cristóvão e Centro - era a promoção de ampliação, articulação e requalificação dos espaços livres de uso público da região portuária da cidade, com vistas à melhoria da qualidade de vida na região e à sua sustentabilidade ambiental e socioeconômica, com particular atenção à criação de pré-condições para o desenvolvimento de empreendimentos ligados à economia criativa. $\mathrm{O}$ projeto ressaltava a decadência da área e sua desvalorização para moradores, turistas e investidores. De acordo com o Censo de 2000, a região ocupava o terceiro lugar de maior déficit de 
crescimento em comparação ao Censo de 1991 (RISCADO, 2015). As obras da primeira fase incluíram a construção de novas redes de água, esgoto e drenagem, a urbanização do Morro da Conceição e a restauração dos Jardins Suspensos do Valongo. Com a conclusão das intervenções, estabeleceu-se um novo padrão de qualidade de serviços prestados na região, como a coleta seletiva de lixo e a iluminação pública eficiente e econômica. Complementando as intervenções urbanísticas, ocorreram também transformações viárias, como a demolição do Elevado da Perimetral, a transformação da Avenida Rodrigues Alves em via expressa e a criação da Via Binário do Porto. Ações de valorização do patrimônio histórico da região, segundo a Companhia de Desenvolvimento Urbano do Porto do Rio de Janeiro (CDURP), visam a contribuir para a promoção do desenvolvimento socioeconômico, bem como a implantação de projetos de impacto cultural, como o Museu de Arte do Rio de Janeiro (MAR), na Praça Mauá, e o Museu do Amanhã, no Píer Mauá (CDURP, 2016). Um dos objetivos era a criação de um ambiente receptivo a empresas e profissionais dos setores criativos, permitindo a eles trocas de ideias e experiências. A Orla da Guanabara Prefeito Luiz Paulo Conde era vista pelo ex-prefeito do Rio de Janeiro Eduardo Paes como um "[...] legado olímpico que representa o encontro da cidade com a Baía de Guanabara, a razão de ser do Rio" (RISCADO, 2015). Trechos do Boulevard Olímpico foram utilizados durante os Jogos Olímpicos de 2016 com atrações especiais, shows e telões para transmissão ao vivo das principais competições.

Com base no suporte conceitual e teórico oferecido pela obra de Charles Landry (2011) e pela sua colaboração com Franco Bianchini (LANDRY; BIANCHINI, 1995), o objetivo do artigo é explicar os méritos e as limitações de processos de regeneração de territórios urbanos que tiveram como um dos eixos condutores o estímulo ao desenvolvimento da economia criativa: a Zona de Intervenção da Expo, em Lisboa, e a Zona Portuária do Rio de Janeiro. Ambos os territórios eram áreas originalmente degradadas localizadas 
próximas ao mar e cujos projetos de regeneração podem ser justificados em parte pelo incentivo ao desenvolvimento da economia criativa.

Quanto às considerações metodológicas, cumpre destacar que, neste estudo, foi feita uma pesquisa bibliográfica, na qual foram coletados dados qualitativos acerca do desenvolvimento da economia criativa em Lisboa e no Rio de Janeiro e também das orientações e dos resultados dos processos de regeneração da Zona de Intervenção da Expo e da Zona Portuária do Rio de Janeiro. A análise do desenvolvimento da economia criativa em ambas as cidades e dos projetos de regeneração foi feita a partir de estudos de caso, os quais, segundo Andrew Bennett (2004), referem-se à análise interna de situações específicas e às comparações entre um pequeno número de casos e lidam com aspectos bem-definidos de um acontecimento histórico selecionado para investigação - neste estudo, Lisboa e Rio de Janeiro como casos de cidades onde se observou o desenvolvimento da economia criativa e a Zona de Intervenção da Expo e a Zona Portuária do Rio de Janeiro como casos de áreas que passaram por projetos de regeneração. Os estudos de caso permitem o alcance de altos níveis de validação e o uso de generalizações contingentes a fim de modelar relações complexas, apesar de terem limitações potenciais, como a dificuldade de se controlarem perfeitamente as comparações entre os casos, além das inerentes, como a inabilidade relativa de se fazer julgamento sobre a frequência ou a representatividade de casos particulares.

Na próxima seção, serão apresentados e debatidos os conceitos de "territórios criativos" e "cidades criativas". A seguir, examinarei por que Lisboa e o Rio de Janeiro podem ser classificadas como cidades criativas a partir dos critérios de cultura, comunicação e cooperação desenvolvidos por Landry (2011) e Landry e Bianchini (1995). E, antes de tecer as considerações finais, analisarei os casos da Zona de Intervenção da Expo e da Zona Portuária do Rio de Janeiro a fim de identificar se a existência de pré-condições físicas para o crescimento das atividades ligadas à economia criativa 
não se mostra suficiente para o desenvolvimento integrado das regiões em foco e o transbordamento de seus benefícios para ambas as cidades, uma vez que podem se manifestar problemas no engajamento dessas regiões com seus entornos, dificuldades de estabelecimento de profissionais criativos nessas áreas e o baixo engajamento da população local nas atividades desenvolvidas no contexto da regeneração, inclusive naquelas voltadas para a economia criativa.

\section{Territórios criativos e cidades criativas}

Territórios como bairros, cidades, estados de uma federação ou regiões que tenham potenciais culturais criativos podem agregar preservação e promoção de valores culturais e ambientais visando a um desenvolvimento integral e sustentável.Um território criativo conta com uma relação entre aspectos sociais, culturais e econômicos no direcionamento das manifestações criativas do espaço, bem como com a diversidade de criatividades de quem faz parte dele (CLOSS et al., 2014). No estudo sobre tais territórios, a noção de "cidade criativa" veio ganhando destaque desde as décadas de 1980 e 1990, em especial na obra de Landry e Bianchini (1995), que associavam o reposicionamento das indústrias culturais no Reino Unido ao aprimoramento das cidades, tendo em vista os possíveis retornos econômicos de atividades e intervenções culturais. A definição de uma cidade criativa transcendia a simples presença de uma classe criativa em seu território, mas abarcava também o estímulo a inovações sociais pela administração pública em setores como saúde, educação e segurança pública. A articulação entre atividades sociais e artísticas, indústrias criativas e governo permitiria atrair talentos, além de estimular a diversidade social e potencializar as habilidades criativas de empresas e instituições, segundo o site Cidade Criativa, Transformações Culturais (CCTC, 2017). Nesse sentido, em uma cidade criativa, o combate às desigualdades faz-se primordial, bem como a atração de talentos e investimentos para regenerar áreas degradadas com base nas especificidades 
locais e a promoção de aglomerações de instituições públicas e privadas que viabilizem empreendimentos e objetivos sociais de regeneração e inclusão social (FOORD, 2008). Como aponta Landry (2011), uma cidade criativa precisa reunir três elementos básicos: a cultura - a identidade da cidade e a imagem que projeta para seu futuro -; a comunicação - meios físicos e tecnológicos para aproximar habitantes e mitigar conflitos -; e a cooperação para a aceitação explícita da diversidade, estimulando-se a abertura mental, a imaginação e a participação pública em soluções potenciais dos problemas urbanos.

Para apoiar o desenvolvimento da economia criativa, as cidades podem utilizar estratégias como o desenvolvimento de negócios, o aconselhamento e a construção de redes, empréstimos diretos para empreendedores criativos, incentivos fiscais e desenvolvimento de infraestrutura física e de tecnologia de informação, frequentemente se destacando as peculiaridades do processo criativo e a construção de habilidades para os negócios (FOORD, 2008). O próprio reconhecimento da criatividade como um recurso territorial conduz à problematização das políticas tradicionais de desenvolvimento urbano e regional e aponta para o estímulo a atividades culturais e ao entretenimento que apresentem potencial para a geração de emprego e renda no espaço urbano (FIGUEIREDO, 2015). Definidas sobre o potencial urbano já existente sem que simplesmente se repliquem modelos já implementados em outras cidades, as pré-condições físicas para que as indústrias criativas possam se desenvolver abarcam tanto uma infraestrutura bruta de edifícios, vias e saneamento básico como uma branda que engloba uma força de trabalho capacitada e flexível e uma infraestrutura intelectual ampla formal e informal (CHANTELOT et al., 2011; LANDRY, 2011). Museus, espaços para exposições, cafés e parques abrem espaço para o desenvolvimento de criatividade e inovação ao atraírem profissionais criativos para a geração de riqueza nas cidades (FLORIDA, 2002; LANDRY, 2011). Ademais, obras e equipamentos atrelados às especificidades urbanas podem 
viabilizar o desenvolvimento do potencial criativo dos que já habitam esses lugares (VIVANT, 2012). A atribuição de novas funções a edifícios patrimoniais dissociados do tecido socioeconômico e a construção de novos edifícios geralmente fazem parte de recuperação patrimonial e histórico-identitária. Tais construções em antigas áreas degradadas de uma cidade podem sinalizar um novo eixo de desenvolvimento ao apresentarem vetores para o reflorescimento das dinâmicas socioculturais e econômicas. Os projetos nos quais essas construções se inserem permitem, em geral, ampliar os mapas mentais dos habitantes sobre sua cidade e fortalecer seu engajamento com regiões por meio da apropriação social do espaço público (REIS, 2011). Áreas históricas renovadas, parques, centros de cultura, museus, salas de espetáculos, feiras e mercados podem ser retratados como atributos das cidades, bem como a diversificação da oferta de bens e serviços. Tais atributos permitem o destaque das cidades na competição por investimentos estrangeiros. Também cumpre destacar que, nesse contexto, grandes eventos internacionais - como competições esportivas ou eventos culturais de grande porte que alimentam setores criativos - podem ser utilizados como justificativas de políticas públicas e projetos de transformação urbana que atraiam tais investimentos (MOURA, 2007).

Todavia, é importante destacar a insuficiência dessas iniciativas de estímulo à economia criativa na condução, por elas mesmas, de grandes modificações urbanas, uma vez que se faz fundamental o diálogo com o entorno de áreas regeneradas, bem como o estabelecimento de parcerias, a promoção do engajamento da comunidade e o desenvolvimento de meios alternativos de financiamento (LANDRY, 2011; REIS, 2011). Constantemente, os efeitos redistributivos negativos dessas iniciativas são ignorados, de maneira que estimulam-se modelos estereotipados de atividades criativas em prejuízo de investimentos em bem-estar social, educação, saúde ou apoio a outras formas de criatividade. As propostas para territórios criativos são compatíveis com o urbanismo neoliberal e o cosmopolitismo competitivo, mas que, na perspectiva 
defendida por seus críticos, apenas remodelaram modelos empreendedores de governança urbana para a atração de capitais altamente voláteis e de profissionais criativos. Cria-se, assim, uma falsa noção de criatividade e habitabilidade para todos os cidadãos, mas o suposto desenvolvimento é orientado para a propriedade e as amenidades (CLOSS et al., 2014). Além disso, os riscos de gentrificação se colocam quando iniciativas voltadas para a regeneração urbana pela cultura e pela economia criativa tornam-se mudanças na articulação de hábitos e de visões de mundo, mas não contribuem para eliminar disparidades na distribuição da renda e da riqueza. Não raramente esse tipo de regeneração aplicou fórmulas pré-concebidas de reestruturação sem a consideração das particularidades do local onde ocorreu, conduzindo-se ao fracasso desse tipo de iniciativa (MILES, 2014). Tal fracasso em geral aparece relacionado ao não engajamento da população do território.

\section{Lisboa como cidade criativa}

Em Portugal, atividades como publicidade, cinema, vídeo, produção de programas de televisão, gravação de som e edição de música, rádio, televisão, livros, jornais e outras publicações representam 3/4 do valor acrescentado bruto (VAB) do Estado. A economia criativa representa cerca de 3,4\% do emprego nacional e 3,3\% dos trabalhadores na Grande Lisboa. Essa região concentra aproximadamente 30\% do emprego criativo em Portugal, com 22 mil empresas no setor. As instituições públicas estimulam o desenvolvimento e a ampliação de redes criativas e fortalecem a ligação dos talentos criativos com o mundo empresarial, o que desemboca na criação de redes de inovação e mais-valias econômicas globais e regionais para a cidade. Potencializa-se a criação de emprego criativo qualificado e se apoia a internacionalização de empresas locais. Dentre os núcleos considerados em Lisboa como "indústrias criativas", cabe destacar os serviços criativos - publicidade, arquitetura e design, incluindo o design 
de moda -; as indústrias culturais - cinema, vídeo, música, rádio e televisão, edição (livros, jornais, revistas), impressão e reprodução (gravação de suportes físicos, tipografias, gráficas) - e as atividades artísticas e culturais, como criação literária (incluindo fotografia, artes performativas e artesanato) e patrimônio cultural, segundo a Câmara Municipal de Lisboa (CML, 2013). A flexibilização do planejamento urbano, a otimização de sistemas de mobilidade, o desenvolvimento de redes de conexão, a transformação de espaços obsoletos e a valorização da sustentabilidade ambiental colocaram-se como condições de possibilidade para o desenvolvimento de tais indústrias (MARTINS, 2011).

Segundo Landry (2011), uma cidade criativa necessita de meios físicos e tecnológicos para aproximar os profissionais criativos. No caso de Lisboa, os profissionais das indústrias criativas tenderam a se concentrar em aglomerações nas quais o ambiente cosmopolita da cidade proporcionou melhores condições para divulgarem seu trabalho. A cidade, assim, reconhece a necessidade multidimensional de se situar não apenas como centro agregador e formador de comunidades criativas mas também centro de inovação e tecnologia, sem que o enraizamento da criatividade conduza a seu isolamento perante outros locais (SALGUEIRO, 2011). É possível registrar um aumento do peso dos serviços criativos e das atividades culturais especialmente na região da Grande Lisboa, diante da procura por serviços intermediários transversais à atividade econômica e do aumento da busca por maiores níveis de formação e de educação nas áreas urbanas. Indústrias como cinema e edição vêm-se deslocando para áreas limítrofes por conta da facilidade de acessos rodoviários e dos custos mais reduzidos no aluguel de espaços físicos. Contudo, é importante destacar que a maior parte das indústrias criativas se concentra nas zonas mais centrais - bem como as atividades destinadas ao ensino - em face da maior acessibilidade e da maior dinâmica dos movimentos culturais urbanos nessas localidades. Novos polos aglutinadores da economia criativa formam-se em zonas da cidade onde no passado se desenvolvia atividade industrial, 
como nos eixos Marvila-Poço do Bispo e Santos-Alcântara (MARTINS, 2011).

Landry (2011) também argumenta que, em uma cidade criativa, o estímulo à cooperação alimentaria a aceitação das diversidades a fim de se estimular o próprio processo criativo e motivar o engajamento das populações na solução de questões urbanas. Quanto ao desenvolvimento de talentos, licenciamse anualmente mais de 1,8 mil estudantes em setores criativos em Lisboa, que se mostra também um polo atrativo de intercambistas por programas internacionais como o Erasmus. No que tange à tolerância, Lisboa demonstra hospitalidade com migrantes e turistas, o que fortalece sua habilidade de captação e de integração de talentos. Com relação à tecnologia, a cidade dispõe de infraestrutura tecnológica, redes de telecomunicações e internet de banda larga de alta qualidade, elementos imprescindíveis ao desenvolvimento de aglomerações criativas. A necessidade de respostas inovadoras à recessão econômica instaurada desde o fim da década de 2010 - para a qual a economia criativa poderia representar uma saída - correlacionou-se com a busca de políticas urbanas que promovam a qualidade de vida e ofereçam equipamentos culturais, lojas e locais de lazer para a atração de talentos e de tecnologia. Nesse contexto, a reabilitação de edifícios e espaços históricos em áreas obsoletas e abandonadas tem como objetivo satisfazer a procura de empreendedores criativos que privilegiam tais áreas na escolha de locais de trabalho. Dentre os exemplos, cabe citar a reabilitação do Palácio Sinel de Cordes para a instalação de uma aglomeração criativa com base na arquitetura, a criação de um espaço de co-working no Mercado do Forno do Tijolo e a instalação das redes de incubadores de empresas Start Up Lisboa. A promoção de bairros e espaços criativos aponta para o desenvolvimento de serviços, a dinamização do comércio de rua e a criação de polos de atração turística. Para tanto, a iniciativa privada mostrou grande expansão na cidade com uma ligação fortalecida aos bairros tradicionais (CML, 2013). 
$\mathrm{Na}$ produção cinematográfica, eventos como os

festivais Indie Lisboa, Doc Lisboa e MotelX contribuem para a dinamização do setor em Lisboa, bem como a atuação de entidades como a Cinemateca e produtoras conceituadas localizadas na cidade. A Lisboa Film Commission busca promover a cidade enquanto destino de filmagens. No âmbito da produção musical, cumpre ressaltar a existência de equipamentos e espaços para festivais, como o Coliseu dos Recreios e o antigo Pavilhão Atlântico. Festivais como o Rock in Rio e o Jazz em Agosto - este último na Fundação Calouste Gulbenkian - são exemplos de eventos ocorridos em Lisboa. O setor de rádio e TV consolida-se com a presença de emissoras de TV- como a RTP - e importantes rádios nacionais na cidade. No segmento de edição, a Feira do Livro de Lisboa conta com cerca de 200 stands, editores e livreiros que apresentam todos os anos desde as últimas novidades até fundos de catálogo. Os serviços criativos como arquitetura, design e publicidade mostram-se mais descentralizados, mas acompanhando as novas áreas de criação e de ensino artístico de Lisboa, em particular no eixo Santos/Cais do Sodré e no Bairro Alto. Novos públicos vêm sendo atraídos para galerias de arte e museus com o fortalecimento de serviços educativos, bem como para as artes performáticas, a maior parcela da atividade cultural com cerca de 30 teatros com programação diversificada, interagindo com outros serviços e indústrias e utilizando as novas tecnologias de informação. No que se refere aos serviços criativos, eventos como o Moda Lisboa contribuíram para posicionar internacionalmente designers portugueses e o evento Open House, organizado pela Trienal de Arquitetura de Lisboa, visou a promover a arquitetura, especialmente a produzida pelos portugueses. No âmbito das atividades artísticas e culturais, cumprem papel importante o Alkantara Festival, que permite a Lisboa um leque diversificado de propostas inovadoras nas artes performáticas; o ILUSTRARTE, um espaço de encontro e discussão sobre ilustração para a infância, e o Belém Art Fest, que se baseia em uma concepção de fusão cultural e consiste na abertura de 
museus à noite com concertos, workshops, exposições e teatro (CML, 2013).

A identidade da cidade permite o desenvolvimento da imagem que ela deseja projetar ao mundo e para o futuro, como lembram Landry (2011) e Landry e Bianchini (1995). Dentre os eventos que permitiram a renovação de Lisboa como cidade criativa e uma nova reflexão sobre sua vida cultural e suas atividades voltadas para o desenvolvimento da economia criativa, cabe destacar a nomeação da cidade como a capital da cultura em 1994. Ainda que algumas regiões da cidade não fossem dotadas de grandes cargas simbólicas, elas ganharam uma nova dimensão ao se criarem condições para múltiplas manifestações culturais, as quais conduziram transformações na forma, na utilização e na imagem desses locais. Ao mesmo tempo em que se presenciou a falência do modelo industrial em algumas áreas da cidade, a década de 1990 permitiu a afirmação de novos modelos econômicos que poderiam dar às cidades uma nova morfologia a partir do desenvolvimento de uma relação simbiótica entre Lisboa e a sua cultura, em particular as atividades da economia criativa. A candidatura, em 1989, à organização da Exposição Mundial de 1998 - no contexto em que também se viriam a celebrar os 500 anos da chegada dos navegadores portugueses à Índia - assentou-se na ideia de recuperar uma parte da cidade que fora relevante nos séculos XVI e XVII, mas que estava em quadro de decadência ao final do século XX: a zona oriental de Lisboa, cuja paisagem degradada trazia um impacto negativo à imagem urbana. Após a Revolução de Abril na década de 1970, as indústrias tradicionais instalavam-se cada vez mais na zona ocidental de Lisboa, área na qual tinham uma rede mais eficaz de serviços. $\mathrm{O}$ declínio industrial da zona oriental apresentava contornos desoladores, com a degradação paisagística. A consciência das entidades governamentais acerca da relevância de se regenerarem espaços devolutos ou degradados foi o pontapé inicial para o projeto da Expo 98 (SALGUEIRO, 2011). 


\section{Rio de Janeiro como cidade criativa}

A cidade do Rio de Janeiro concentra cerca de $80 \%$ da renda e do emprego da economia criativa do estado da federação. A concepção do Rio de Janeiro como cidade criativa coloca a economia criativa como plataforma de desenvolvimento local para a mobilidade social a partir de ações governamentais, o que caminha lado a lado com a construção de uma "cultura de criatividade" - que represente o cotidiano social e possibilite a identificação do sujeito com o capital cultural produzido no território - e o desenvolvimento de uma vitrine internacional de reinvenção da cidade sob bases simbólicas para a atração de negócios e talentos (WANIS, 2013). No que diz respeito ao desenvolvimento de uma plataforma de desenvolvimento local, a cultura desponta como um dispositivo necessário ao alívio de tensões sociais, bem como um instrumento de transformação urbana, desenvolvimento econômico e inclusão social. Com o apoio e a implementação de projetos criativos locais, a prefeitura - que assumiu a função de protagonista na articulação de esferas governamentais e de agentes externos (APRIGIO, 2015) - visou a ampliar a produção cultural, expandir a rede de espaços culturais públicos e disseminar o acesso à cultura. Na direção apontada por Landry (2011), o governo procurou a articulação com as indústrias criativas e os produtores culturais a fim de criar um espaço que permitisse a vinda de profissionais criativos e fortalecesse a diversidade e as capacidades de empreendimentos criativos, em especial na viabilização de iniciativas de regeneração de áreas degradadas e de inclusão social.

Em termos da criação de uma "cultura de criatividade" para a consolidação de uma identidade criativa da cidade - o que visa ao estabelecimento de uma imagem que se pretende projetar para o exterior (LANDRY, 2011; LANDRY; BIANCHINI, 1995) -, o programa de apoio à economia criativa pela prefeitura do Rio de Janeiro foca em áreas como produção, comercialização, infraestrutura e treinamento nas atividades criativas, particularmente em setores como cinema 
e TV. Por exemplo, com a função de desenvolver a indústria do audiovisual - colocando a cidade como o maior centro de indústrias do setor no Brasil -, a Empresa Distribuidora de Filmes S.A. - RIOFILME investiu em cerca de 300 filmes de longa-metragem e 130 de curta-metragem desde o início da década de 1990 (FIGUEIREDO, 2015; WORLD CITIES CULTURE FORUM, 2015). Tem papel importante nesse processo de criação da "cultura de criatividade" a realização de eventos culturais de grande porte, como os desfiles das escolas de samba durante o Carnaval, e os festivais musicais, como o Rock in Rio. No que diz respeito ao desenvolvimento de uma vitrine internacional, o Rio de Janeiro procurou criar uma interligação mais estreita entre inovação e qualidade de vida, bem como divulgar sua imagem no exterior pelos eventos socioculturais realizados na cidade e seus bairros e atrações turísticas. As exportações de moda, por exemplo, assumiram elevado valor agregado pelo conteúdo simbólico e intangível mais alto, o que atrai consumidores dispostos a pagar mais caro por produtos. A prefeitura buscou parcerias com os governos federal e estadual a fim de que grandes eventos como os Jogos Olímpicos e Paralímpicos de 2016 abrissem mais oportunidades para o desenvolvimento de setores criativos na cidade. A Rio Negócios - Agência de Promoção de Investimentos do Rio de Janeiro - procura captar e facilitar novos investimentos e oferecer apoio em promoção comercial e inteligência de negócios. Além disso, encontros de negócios como as Rio Conferences buscam atrair investimentos para a economia criativa, ocorrendo, inclusive, durante eventos esportivos (APRIGIO, 2015).

Iniciativas de regeneração de áreas da cidade almejam a atração de empresas criativas (MÈRCHER, 2013). A pressão de empreendimentos imobiliários, redes hoteleiras e conglomerados de entretenimento fez com que tais atores se apropriassem das identidades locais para se estabelecerem em áreas da cidade potencialmente lucrativas, como a região portuária. Grandes equipamentos culturais de projeção internacional foram desenvolvidos na região, como o MAR, 
inaugurado em 2013, e o Museu do Amanhã, projeto arquitetônico do espanhol Santiago Calatrava (WANIS, 2013), inaugurado em 2015. Obras feitas para abrigar espaços culturais - como a Cidade das Artes na Barra da Tijuca e o novo Museu da Imagem e do Som na praia de Copacabana - visam também à atração de shows e exposições nacionais e internacionais para a cidade, bem como a vinda e a permanência de profissionais de setores criativos na cidade.

Os temas relacionados à economia criativa foram inseridos nas agendas políticas da cidade do Rio de Janeiro no início da década de 2000, com a criação da Superintendência da Economia da Cultura do Governo do Estado. O debate acerca da temática se intensificou com o primeiro evento da conferência da Conferência das Nações Unidas sobre Comércio e Desenvolvimento (UNCTAD, na sigla em inglês) sobre economia criativa em 2004 e, posteriormente, com a criação de gerências de economia criativa em instituições como o Serviço Brasileiro de Apoio às Micro e Pequenas Empresas (SEBRAE) e o Banco Nacional de Desenvolvimento Econômico e Social (BNDES). A relevância das indústrias criativas foi reforçada com o anúncio da cidade como sede olímpica e o recebimento do título de Patrimônio Mundial da Humanidade pela Organização das Nações Unidas para a Educação, a Ciência e a Cultura (UNESCO, na sigla em inglês). O Rio de Janeiro serviu como sede do $1^{\circ}$ Festival Internacional de Criatividade (CRIO) e gradualmente passou a adotar estratégias de internacionalização, como a contratação de arquitetos renomados para a realização de grandes obras voltadas ao desenvolvimento de artes e cultura, de musicais internacionais e de filmes estrangeiros com locações no Rio de Janeiro. A atração de grandes franquias culturais passou a ser concebida como alternativa considerável para a requalificação urbana. Eventos como os Jogos Mundiais Militares e o Fórum Econômico Mundial em 2011, a Jornada Mundial da Juventude e a Copa das Confederações da FIFA em 2013, a Copa do Mundo da FIFA em 2014 e os Jogos Olímpicos e Paraolímpicos de 2016 foram vistos como meios de 
promoção global do Rio de Janeiro, fortalecendo seu status de economia em crescimento e destino turístico e trazendo uma oportunidade para o desenvolvimento da economia criativa carioca. Com isso, também se busca a adesão social ao projeto de cidade criativa (WANIS, 2013). A Empresa de Turismo do Município do Rio de Janeiro S.A. (RioTur) procurou atrair o êxodo turístico nacional e internacional, atuando em conjunto com a iniciativa privada (APRIGIO, 2015).

\section{A Zona de Intervenção da Expo}

A candidatura de Lisboa para sediar a Exposição Mundial de 1998 foi apresentada em 1989, o que se relacionava a um trabalho de planejamento, concepção, construção e gestão que buscava promover o encontro da cidade com o rio Tejo. A aprovação ocorreu em 1992. A disponibilidade imediata de solo público e acessos facilitados do norte de Portugal e da Espanha, bem como do aeroporto, foram fundamentais para a escolha da área situada na parte oriental da cidade. Tinha-se a possibilidade de regeneração da área até então constituída por instalações industriais poluidoras e obsoletas (SCHERER, 2003). A antiga Doca dos Olivais, região onde atracavam hidroaviões no passado, transformou-se em um terreno industrial bastante degradado. Tal região era uma área portuária impregnada de lixo industrial, reservatórios e materiais obsoletos, que seria regenerada ao se trazerem novas infraestruturas culturais, comerciais e ferroviárias e um novo parque habitacional. $\mathrm{Na}$ orla ribeirinha, o lixo industrial amontoado criava uma barreira que impedia que o conjunto de áreas residenciais, desenvolvidas no interior da cidade a partir da década de 1940, beneficiasse-se do Rio Tejo. A ideia era a de que, quando fosse encerrada a exposição, o recinto pudesse ser transformado em cidade corrente, ancorada em equipamentos excepcionais. $O$ planejamento vinculava a ideia de um resgate urbano para o oriente e uma cultura de regresso ao rio. O tema escolhido para a exposição - "Os oceanos: um patrimônio para o futuro" - permitia dar início a uma onda de 
novas exposições, tendo como pano de fundo a consciência dos problemas levantados pela exploração sistemática dos recursos oceânicos e a necessidade de se desenvolverem propostas para o equilíbrio ambiental. Além disso, em face dos 500 anos da chegada de Vasco da Gama à Índia, a simbologia relativa ao mar não foi relegada em segundo plano no projeto da exposição. A zona de intervenção foi segmentada em planos de pormenores, que ficaram a cargo de diferentes equipes de arquitetos. Durante a Expo 98, foram construídos dois tipos de pavilhões: os temáticos da responsabilidade da Parque Expo e os pavilhões das Regiões Autônomas, entidades convidadas e patrocinadores. Após o fim do evento, houve alterações no parque, renomeado Parque das Nações. A entrada principal em frente à estação intermodal - Gare do Oriente, obra do arquiteto Santiago Calatrava - foi reconvertida no Centro Vasco da Gama. A zona internacional norte passou a acolher a Feira Internacional de Lisboa, e o Pavilhão da Utopia passou a se chamar Pavilhão Atlântico - hoje MEO Arena -, espaço no qual se realizam grandes eventos como competições esportivas, musicais, feiras e pressrooms. Destacam-se também o Oceanário de Lisboa, o Pavilhão do Conhecimento - que abriga um museu de ciência - e o Pavilhão do Futuro, que foi transformado no Casino Lisboa (FIGUEIRA, 2010; SALGUEIRO, 2011).

A proximidade do aeroporto internacional, da marina e das principais estradas de acesso à cidade e a construção de instalações como a Gare do Oriente e a Ponte Vasco da Gama permitiram a configuração de um novo centro para a área metropolitana, que poderia se mostrar atraente para empresas do setor criativo por conta da infraestrutura bruta desenvolvida. Gradualmente, áreas do Parque das Nações foram sendo vendidas para habitação e escritórios. Ao fim do processo de venda de terrenos, as receitas tinham superado o custo da exposição em oito vezes. Nos dias atuais, a zona oriental de Lisboa é a parte mais moderna da cidade. A concentração de áreas comerciais, culturais e de lazer, com uma vista privilegiada do rio Tejo e do Mar da Palha (um mar 
interior no estuário do rio, próximo da sua foz), captou uma série de instituições e empresas ligadas à economia criativa, que instalaram na região suas sedes ou representações, como a Sony Corporation. Aspectos de ocupação comerciais, residenciais e de lazer, além dos espaços verdes, combinam-se para a atração de empresas e profissionais criativos. As zonas comerciais dispersas pelo recinto e a área do Centro de Negócios são apoiadas por um conjunto de hotéis e pelo Centro Comercial Vasco da Gama. As partes residenciais concentram-se junto à marina e ao Parque do Tejo e do Trancão, estando muitas delas rodeadas por espaços verdes e tendo ao redor escolas e postos de saúde. Com respeito ao lazer, existem restaurantes, bares e comércio especializado, bem como equipamentos esportivos (SCHERER, 2003). Estão previstos para a região eventos como I Rio Lisboa Content Market, que terá entre seus principais objetivos difundir e ampliar a participação dos conteúdos audiovisuais dos Estados de Língua Portuguesa no mundo e estimular o desenvolvimento das indústrias criativas na região.

Entretanto, uma das principais críticas feitas ao empreendimento remete aos modelos de habitação, que seguiram os das operações imobiliárias convencionais, mas com custos socioeconômicos muito maiores. Além disso, ainda que se configure como uma ilha de excelência, o Parque das Nações mostrou-se pouco permeável ou fomentador da regeneração mais alargada da cidade, concentrando equipamentos junto ao rio e ao seu estuário e favorecendo o caráter não reprodutível da área matriz (FIGUEIRA, 2010). Pode-se mencionar a falta de maior integração da área oriental com o entorno. Ademais, os planos de pormenores atenderam às especificidades de cada situação, mas também denotaram incongruências ao introduzirem diferentes critérios para parcelas vizinhas e faltar continuidade em áreas específicas da intervenção (SCHERER, 2003). Os edifícios construídos não possuem forte ligação com o ambiente que os rodeia, com criações arquitetônicas de exceção (SALGUEIRO, 2011). Manuel Villaverde Cabral (1999) argumenta que a região se 
configurou como um “[...] enorme gueto de luxo - com uma bonita vista para o Mar da Palha, mas de costas voltadas para a cidade".

Ademais, a população do Parque das Nações é predominantemente jovem, com elevado nível socioeconômico. A maior parte das pessoas que vivem na região tem veículo próprio, uma vez que a rede de transportes alternativa ainda não parece totalmente agilizada e integrada na zona oriental de Lisboa. Falta uma rede de transportes internos que viabilize a circulação entre as várias zonas do Parque diante da indefinição das autoridades competentes quanto a um compromisso para administrar a zona no que diz respeito à mobilidade. Tal situação aponta para o desvirtuamento de metas colocadas no modelo de gestão urbana quanto à adoção de mobilidade sustentável, questão que não foi definitivamente solucionada em virtude de constrangimentos de trânsito e estacionamento errático, e que cria problemas para a integração entre as atividades de empresas e profissionais criativos que se estabeleçam ou queiram se estabelecer na região. A Gare do Oriente permite a facilidade da confluência de transportes para aqueles que vivem em sua proximidade, mas, em face da falta de abrangência da rede de transportes públicos, os habitantes de outras áreas mais afastadas da estação dependem muito mais do automóvel. A questão habitacional também se tornou controversa, pois, no projeto original, imaginava-se que a região seria ocupada exclusivamente pela classe média, mas, alguns anos depois, a maioria das habitações tem elevado custo por metro quadrado. Assim, seus principais destinatários acabaram sendo pessoas de classes média e média alta, que abarcam uma parcela de profissionais criativos, mas apenas aqueles de mais alta renda (a minoria no setor). Mesmo para essas pessoas, o modelo urbano trouxe dificuldade na conjugação entre trabalho e habitação, o que dificulta a criação de um sentimento de identificação total com o território. As fracassadas tentativas de se fixarem pessoas de classes sociais distintas mostram que o Parque das Nações não se coloca como uma região verdadeiramente integrada à realidade 
social de Lisboa (SALGUEIRO, 2011), e os efeitos de transbordamento de benefícios de uma área regenerada, tendo o potencial desenvolvimento da economia criativa como seu vetor de transformação, são limitados.

Algumas empresas ligadas à economia criativa e aliadas à tecnologia se estabeleceram no Parque das Nações, em particular empresas de artes, publicidade e design como Creative Minds, Idea, Strat e Superideias. Enquanto na parte ocidental de Lisboa está estabelecida a maior parte dos interesses estratégicos e financeiros, a zona oriental hoje traz a concentração tecnológica, o que apontaria para uma descentralização econômica da cidade. Entretanto, muitas empresas criativas estabelecidas na região mostram-se cerradas nelas mesmas, ao mesmo tempo em que as infraestruturas criativas e culturais não foram devidamente acauteladas. Devido aos altos custos da região, os profissionais criativos não conseguem se fixar na região, além de que os custos elevados da área não são convidativos ao estabelecimento de estruturas criativas de pequeno e médio portes (SALGUEIRO, 2011).

\section{A Zona Portuária do Rio de Janeiro}

As ações de regeneração da Zona Portuária do Rio de Janeiro abarcaram a conservação e manutenção do sistema viário e de áreas verdes e praças, a manutenção e o reparo de iluminação pública e calçadas, a execução de serviços de limpeza urbana, a manutenção da rede de drenagem e de galerias universais e da sinalização de trânsito, a instalação e a conservação de bicicletários e a conservação de pontos e monumentos turísticos, históricos e geográficos. Regras ambientais orientam as ações, como o reaproveitamento de águas pluviais e servidas, a geração local de energias limpas e o uso de aquecimento solar e de telhados verdes. Com a preocupação de estimular a permanência dos atuais moradores na região portuária, parte dos recursos obtidos com a venda de certificados para a exploração de potencial construtivo na região é investida na valorização do patrimônio material 
e imaterial da área e em programas de desenvolvimento social, além da oferta de habitações de interesse social, da integração entre os diversos modais de transporte público, da recuperação da qualidade ambiental da área e da geração de empregos diretos e permanentes na região (CDURP, 2016). Iniciativas do processo de regeneração da área abarcam a construção de um aquário público - ação importante para o turismo, o entretenimento e a pesquisa científica -, a nova sede do Banco Central, a fábrica de espetáculos do Theatro Municipal e a extensão da Biblioteca Nacional, além do incentivo a equipamentos culturais anteriormente escondidos sob o Elevado da Perimetral (RIOETC, 2015).

As ações voltadas ao patrimônio mostraram-se mais complexas, em especial no que diz respeito ao material arqueológico encontrado nas escavações feitas no Cais do Valongo e no Cais da Imperatriz, locais de desembarque e comércio de escravos africanos. Além disso, os projetos Porto Maravilha Cidadão e o Porto Maravilha Cultural almejam a realização de uma modernização urbana inclusiva em termos socioeconômicos e culturais. O primeiro programa apoia programas de habitação de interesse social, formação profissional e requalificação profissional para moradores, bem como ações de empreendedorismo e educação para a cidadania. Já o segundo busca a recuperação e a restauração material do patrimônio artístico e/ou arquitetônico, a valorização do patrimônio cultural imaterial, a preservação da memória e das manifestações culturais e a exploração econômica do patrimônio material e imaterial, respeitados os princípios de integridade e sustentabilidade do patrimônio. Porém, pouco vem sendo realmente feito no que diz respeito ao patrimônio cultural além do levantamento dos bens e instituições culturais na região e a realização do Prêmio Porto Maravilha Cultural para projetos culturais com atividades na zona portuária. Cursos, shows, oficinas, festas, publicações e documentários compõem a lista de atividades que buscam estimular o desenvolvimento cultural da região (RISCADO, 2015). 
A fim de estimular o desenvolvimento da economia criativa na região, foi criado em 2015 o Distrito Criativo do Porto, uma iniciativa inspirada em experiências semelhantes em cidades como Barcelona e Miami e que reúne uma rede de empreendedores em parceria com a CDURP para promover oportunidades de negócios para os empresários da cidade. A iniciativa é composta por dezenas de empresas e coletivos dessa nova indústria, já instalados no entorno do Santo Cristo, da Gamboa, da Praça Mauá e do Morro da Conceição. Entre os projetos previstos, cabe destacar a criação de programas de capacitação de mão de obra, a consolidação e a ampliação do calendário cultural e a promoção de rodadas de negócios para divulgar a produção local (BOECKEL, 2015). O Coletivo do Porto é composto por cinco empresas do setor criativo que compartilham espaço, ideias e experiências para criar soluções integradas em comunicação, marketing, desenvolvimento digital e projetos relacionados à inovação e a design, enquanto o Coletivo Goma é constituído por empresas focadas em inovação e criatividade, com atividades que priorizam o desenvolvimento sustentável, arte e design. No contexto do desenvolvimento do Distrito Criativo, a antiga fábrica de chocolates Bhering abriga ateliês, estúdios e oficinas de profissionais criativos. No local, artistas e criadores organizam eventos com mostras, performances musicais e parcerias culturais. No âmbito do programa Porto Maravilha Cidadão, a Feira do Porto reúne artesanato, culinária, cultura e música tradicionais na Saúde (CDURP, 2016).

Contudo, as iniciativas desenvolvidas na Zona Portuária configuram-se como excessivamente fragmentadas e com pouca interação entre elas, em especial entre os novos equipamentos urbanos e as iniciativas voltadas para o patrimônio histórico da região. A falta de diálogo entre o presente e o passado da zona portuária e de uma efetiva integração entre essas iniciativas pode ser justificada pelo baixo engajamento das populações locais. Apesar da diversidade de iniciativas para a inclusão dessa população, muitas dessas iniciativas são dotadas de recursos escassos ou têm alcance 
limitado em razão da quantidade de pessoas que vivem na área e poderiam se beneficiar delas, em especial as mais pobres que habitam os morros da região. Como lembra Julia Ermínia Riscado (2015), o próprio processo de implementação da política de regeneração vem afetando a população de baixa renda local ao trazer um aumento de custos de bens e serviços e assim dificultar a permanência de antigos moradores de renda insuficiente para sua manutenção no local. O modelo mostra-se excludente, uma vez que a reativação da economia no local antes degradado não pressupôs o efetivo engajamento da população local, que se mostra pouco envolvida inclusive nas iniciativas culturais que visam a manter a pluralidade de valores e usos que compõem os centros antigos da cidade e no desenvolvimento do potencial econômico das atividades culturais que poderiam ser realizadas na área.

Como a área tem um perfil de vida urbana cíclica, ela se mantém muito movimentada durante o dia, mas se esvazia durante a noite. Uma das iniciativas pensadas para solucionar o problema é o estímulo às áreas residenciais na região, focando especialmente os jovens empreendedores que não teriam condições de se manter em áreas extremamente valorizadas da cidade, como a zona sul. Muitos esforços no sentido de atração de moradores para a região enfatizam a integração entre os meios de transporte, ainda que nos dias atuais a mobilidade esteja prejudicada pelas obras ainda em andamento (RIOETC, 2015). Todavia, os investimentos na segurança pública na região não se mostraram suficientes para conter a realização de delitos, o que afasta a classe criativa e dificulta a fixação daqueles profissionais que veem benefícios em potencial na região. É nítido também que as iniciativas culturais baseadas nas tradições locais recebem menos investimentos do que os equipamentos de maior porte como o MAR e o Museu do Amanhã, que ocupam papel importante no marketing urbano e na atração de visitantes e turistas para a região. Ademais, apesar da ênfase dos projetos na sustentabilidade, é possível observar o descarte irregular de lixo em áreas como o gramado no entorno do Museu do Amanhã e o lixo acumulado na Baía de 
Guanabara, perto do equipamento cultural, o que se afasta dos objetivos de desenvolvimento com base na economia criativa. Novamente, observa-se o baixo envolvimento das populações locais em face da lacuna de um processo educacional que não apenas estimule a criatividade e a exploração de seu potencial econômico, mas também desperte a consciência de preservação da memória da região para reflexões e críticas sobre opções de desenvolvimento para o local e a importância da preservação ambiental para a melhoria da qualidade de vida das populações que habitam e visitam a Zona Portuária.

\section{Considerações finais}

Ainda que Lisboa e o Rio de Janeiro possam ser consideradas cidades criativas por reunirem os critérios de cultura, comunicação e cooperação desenvolvidos por Landry (2011), os projetos de regeneração urbana examinados nesta pesquisa provam que a construção de territórios criativos em tais áreas ficou aquém do esperado, pois, ainda que tenham minimamente dotado e capacitado tais regiões com infraestrutura bruta, elas não atenderam a elementos fundamentais ao desenvolvimento socioeconômico apontados por Landry (2011) e Landry e Bianchini (1995). Tanto na Zona de Intervenção da Expo como na Zona Portuária do Rio de Janeiro, foi possível observar a baixa integração de tais áreas com seu entorno, os obstáculos ao estabelecimento e à fixação de profissionais criativos ainda que por motivos diferentes em ambas as regiões - e o reduzido engajamento das populações locais nas atividades relacionadas à economia criativa.

Em face de tais limitações, políticas públicas para territórios criativos mostram-se fundamentais para a definição de prioridades no desenvolvimento desses locais, o direcionamento de recursos para a execução de obras estratégicas e a coordenação de diferentes níveis de governo para a captação de recursos, mas também para o estímulo à participação pública, a integração da população ao mercado 
de trabalho e o incentivo à criação e ao fortalecimento dos negócios locais. Ainda que os casos da Zona de Intervenção da Expo e da Zona Portuária do Rio de Janeiro tenham revelado a preocupação com o estímulo aos negócios locais e ao turismo, pouco pôde ser observado no que diz respeito especificamente à integração dos habitantes da própria região nas iniciativas propostas. É possível observar processos de gentrificação em curso nesses locais - que acabam afastando a classe criativa menos abastada da vida e do trabalho naqueles territórios - e de guetificação das indústrias criativas ali situadas, com o transbordamento limitado de benefícios para as próprias regiões e seus entornos.

Os projetos e as políticas públicas que poderiam contribuir para fortalecer a cultura empreendedora local e o engajamento efetivo da população nas atividades englobam a criação de incubadoras de empresas criativas que aproveitem a mão de obra local em suas atividades, a maior divulgação de feiras e exposições para dinamização do comércio local, a geração e a manutenção da infraestrutura necessária à produção e comercialização de bens e serviços criativos, a inclusão efetiva dessas populações em programas de educação empreendedora nas regiões com recursos adequados, a facilitação do acesso à tecnologia e ao crédito e a desburocratização para a implementação de pequenos e médios empreendimentos pela população local. Mostra-se também primordial que lideranças locais de grupos da sociedade civil sejam envolvidas nos projetos e capacitadas para uma melhor compreensão dos processos de formulação e de planejamento de políticas públicas e contribuir para a gestão dos assuntos locais com relação à economia criativa (LOPES; AMARAL, 2008, p. 33-37).

\section{Referências}

APRIGIO, André Edson Ribeiro de Souza. A paradiplomacia e a atuação internacional de governos subnacionais. 2015. Dissertação (Mestrado em Relações Internacionais) - Departamento de Relações Internacionais e Administração Pública, Escola de Economia e Gestão, Universidade do Minho, Minho, 2015. 
BENDASSOLLI,Pedro F.; WOODJR.,Thomaz; KIRSCHBAUM, Charles; CUNHA, Miguel Pina e. Indústrias criativas: definição, limites e possibilidades. RAE, v. 49, n. 1, p. 10-18, 2009.

BENNETT, Andrew. Case study methods: design, use, and comparative advantages. In: SPRINZ, Detlef F.; WOLINSKYNAHMIAS, Yael (Ed.) Models, numbers, and cases: methods for studying International Relations. Ann Arbor: The University of Michigan Press, 2004. p. 19-55.

BOECKEL, Cristina. Distrito Criativo do Porto é criado para buscar negócios após Rio 2016. 12 ago. 2015. G1. Disponível em: <http:// g1.globo.com/rio-de-janeiro/olimpiadas/rio2016/noticia/2015/08/ distrito-criativo-do-porto-e-criado-para-buscar-negocios-aposrio-2016.html>. Acesso em: 4 dez. 2017.

CABRAL, Manuel Villaverde. A montanha e o rato. Notas à margem de um dossier sobre a Expo depois da Expo. In: FERREIRA, Vítor Matias; INDOVINA, Francesco (Ed.).A cidade da EXPO'98. Uma Reconversão na Frente Ribeirinha de Lisboa?. Lisboa: Bizâncio, 1999. p. 331-341. (Coleção Documentos).

CÂMARA MUNICIPAL DE LISBOA. Lisboa - Economia Criativa. Lisboa: Câmara Municipal de Lisboa, 2013.

CIDADE CRIATIVA, TRANSFORMAÇÕES CULTURAIS. Cidade criativa. 2017. Disponível em: <http://cidadecriativa.org/ pt/cidade-criativa>. Acesso em: 8 set. 2017.

CHANTELOT, Sébastien; PÉRÈS, Stéphanie; VIROL, Stéphane. From Talent to Creative Cities: Toward a Conceptual Framework. In: EUROPEAN CONGRESS OF THE REGIONAL SCIENCE ASSOCIATION INTERNATIONAL, 51.,NEW CHALLENGES FOR EUROPEAN REGIONS AND URBAN AREAS IN A GLOBALISED WORLD, 2011.

CLOSS, Lisiane Quadrado; OLIVEIRA, Sidinei Rocha de; AZEVEDO, Patrícia Rodrigues de; TIRELLI, Christian. Das Cidades aos Territórios Criativos: um Debate a Partir das Contribuições de Milton Santos. In: ENCONTRO DA ANPAD, 38., Rio de Janeiro, 13-17 set. 2014, Rio de Janeiro. Anais... Rio de Janeiro: ANPAD, 2014. p. 1-15.

COMPANHIA DE DESENVOLVIMENTO URBANO DO PORTO DO RIO DE JANEIRO. CDURP. Apresentação da Operação Urbana. Porto Maravilha website, 2016. Disponível em: $<$ http://www.portomaravilha.com.br/portomaravilha>. Acesso em: 4 dez. 2017. 
COMUNIDADEDOS PAÍSES DE LÍNGUA PORTUGUESA.

Economia Criativa em Língua Portuguesa debatida em Lisboa. 27 maio 2013. Disponível em: <http://www.cplp.org/id-4211.aspx?P $\mathrm{ID}=10035 \& \mathrm{M}=\mathrm{News}$ 2\&Action=1\&NewsId=2811\&currentPa ge=13>. Acesso em: 4 dez. 2017.

ENCONTRO DA ECONOMIA CRIATIVA LUSÓFONA. ECL. 2015. Disponível em: <http://www.encontroecl.com/\#sobre>. Acesso em: 4 dez. 2017.

FIGUEIRA, Jorge. A Expo 98 de Lisboa: projeto e legado. ARQTexto, n. 16, p. 152-163, 2010.

FIGUEIREDO, João Luiz de. Economia criativa, cidade criativa e desenvolvimento. In: TEIXEIRA, Eduardo Ariel de Souza; CORREAA, Sílvia Borges (Org.). Economia criativa. Rio de Janeiro: E-papers, 2015. p. 27-47. (Coleção Contextos e Pesquisas).

FLORIDA, Richard. The rise of the creative class - and how it's transforming work, leisure, community and everyday life. Nova York: Basic Books, 2002.

FOORD, Jo. Strategies for creative industries: an international review. Creative Industries Journal, v. 1, n. 2, p. 91-113, 2008.

LANDRY, Charles. Prefácio. In: REIS, Ana Carla Fonseca; KAGEYAMA, Peter (Org.). Cidades criativas: perspectivas. São Paulo: Garimpo de Soluções, 2011. p. 7-15.

1998.

.; BIANCHINI, Franco. The creative city. Londres: Demos,

LOPES, Brenner; AMARAL, Jefferson Ney. Políticas Públicas: conceitos e práticas. Belo Horizonte: Sebrae MG, 2008.

MARTINS, Rolando Borges. Lisboa, criativa? In: REIS, Ana Carla Fonseca; KAGEYAMA, Peter (Org.). Cidades criativas: perspectivas. São Paulo: Garimpo de Soluções, 2011. p. 78-83.

MÈRCHER, Leonardo. Museu de Arte do Rio e Museu do Amanhã: duas ferramentas à paradiplomacia cultural do Rio de Janeiro. In: MONTEIRO, Rosana Horio; ROCHA, Cleomar de Souza (Org.). Anais do VI Seminário Nacional de Pesquisa em Arte e Cultura Visual. Goiânia: UFG, FAV, 2013. p. 101-111.

MIGUEZ, Paulo. Economia criativa: uma discussão preliminar. In: NUSSBAUMER, Gisele Marchiori (Org.). Teorias e políticas da cultura: visões multidisciplinares. Salvador: EDUFBA, 2007. p. 95113. 
MILES, Steven. A revitalização movida pela cultura funciona?. In: GOLDENSTEIN, Lidia; ROSSELLÓ, Pablo; ARRUDA, Felipe (Coord.). Regeneração urbana através da cultura funciona?. Londres, São Paulo: The British Council, 2014. p. 124-132.

MOURA, Rosa. O Turismo no Projeto de Internacionalização da Imagem de Curitiba. Turismo - Visão e Ação, v. 9, n. 3, p. 341-357, 2007.

REIS, Ana Carla Fonseca. Economia da cultura e desenvolvimento sustentável: O caleidoscópio da cultura. Barueri: Manole, 2006.

- Introdução. In:

(Org.) Economia criativa como estratégia de desenvolvimento: uma visão dos países em desenvolvimento. São Paulo: Itaú Cultural, 2008. p. 14-49.

- Revelando o invisível: os enredados fios de ligação entre ícones culturais e os processos de transformação urbana. In: - (Org.). Anais do Seminário Internacional Cultura e Transformação Urbana. São Paulo: SESC Belenzinho, 2011. p. 10-14.

RIOETC. Muito prazer, Distrito Criativo do Porto. RioETC website, 7 ago. 2015. Disponível em: <http://www.rioetc.com.br/ muito-prazer/muito-prazer-distrito-criativo-do-porto/>. Acesso em: 4 dez. 2017.

RISCADO, Júlia Erminia. Política de requalificação dos centros históricos no contexto das operações urbanas consorciadas: o caso do Porto Maravilha. In: CALABRE, Lia; SIQUEIRA, Mauricio; LIMA, Deborah Rebello; ZIMBRÃO, Adélia (Org.). Anais do VI

Seminário Internacional de Políticas Culturais. Rio de Janeiro: Fundação Casa de Rui Barbosa, 2015. p. 774-784.

SALGUEIRO, Luís Filipe Oliveira Marques. Cidade e Utopia: reconstrução da zona oriental de Lisboa. O projecto do Parque das Nações. 2011. Dissertação (Mestrado em Ciências da Cultura) Faculdade de Letras, Universidade de Lisboa, Lisboa, 2011.

SCHERER, Fabiano de Vargas. Aspectos urbanísticos da Exposição Internacional de Lisboa 1998. Arquitextos, ano 4, jul. 2003. Disponível em: <http://www.vitruvius.com.br/revistas/read/ arquitextos/04.038/666>. Acesso em: 4 dez. 2017.

VIVANT, Elsa. O que é uma cidade criativa? São Paulo: Senac, 2012.

WANIS, Amanda. Cidade Criativa: política urbana e cultural na reconstrução simbólica do Rio Olímpico. In: CONFERÊNCIA 
INTERNACIONAL MEGAEVENTOS E A CIDADE, 2., Rio

de Janeiro, 27-30 abr. 2013. Rio de Janeiro. Anais... Rio de Janeiro,?, 2013. Disponível em: <http://megaeventos.ettern.ippur.ufrj.br/ sites/default/files/artigos-cientificos/wanis_a._cidade_criativa.pdf $>$. Acesso em: 4 dez. 2017.

WORLD CITIES CULTURE FORUM. Rio de Janeiro. 2015.

Disponível em: <http://www.worldcitiescultureforum.com/cities/ rio-de-janeiro>. Acesso em: 4 dez. 2017.

Submetido em: 09/08/2017

Aceito em: 12/12/2017 
156 Revista Grifos

\title{
NEAR SEA, DISTANT TOWN: CREATIVE ECONOMY AND URBAN REGENERATION IN LISBON AND RIO DE JANEIRO
}

\begin{abstract}
Based on the theoretical framework of Charles Landry and his collaboration with Franco Bianchini, the aim of the article is to explain the merits and the limitations of the regeneration processes in urban areas, which had as one of the driving forces the stimulus to the creative economy: the Expo Intervention Zone in Lisbon and the Harbour Area of the city of Rio de Janeiro. The methodology was based on a bibliographical research, with the mobilization of qualitative data. The research indicates that the results were below expectations due to the difficulties of integrating these regions with their environments, the fixation problems of the creative professionals and the low incentive to the engagement of the local population in the main activities related to the creative sectors.
\end{abstract}

Keywords: Creative economy; Urban regeneration; Lisbon; Rio de Janeiro. 